\title{
Lurasidone as a potential therapy for bipolar disorder
}

This article was published in the following Dove Press journal:

Neuropsychiatric Disease and Treatment

7 October 2013

Number of times this article has been viewed

\section{Young Sup Woo \\ Hee Ryung Wang \\ Won-Myong Bahk}

Department of Psychiatry, Yeouido St Mary's Hospital, The Catholic University of Korea, Seoul, Korea
Correspondence: Won-Myong Bahk Department of Psychiatry, Yeouido St Mary's Hospital, The Catholic University of Korea, \#62, Yeouido-Dong, Youngdeungpo-Gu, Seoul, Korea

Tel +82237791250

Fax +82 27806577

Email wmbahk@catholic.ac.kr
Abstract: Lurasidone is a benzisothiazol derivative and an atypical antipsychotic approved by the US Food and Drug Administration for the acute treatment of adults with schizophrenia (October 2010) and bipolar 1 depression (June 2013). Lurasidone has a strong antagonistic property at the $\mathrm{D}_{2}$, serotonin $(5-\mathrm{HT})_{2 \mathrm{~A}}$, and $5-\mathrm{HT}_{7}$ receptors, and partial agonistic property at the 5-HT $1 \mathrm{~A}$ receptor. Lurasidone also has lower binding affinity for the $\alpha_{2 \mathrm{C}}$ and 5- $\mathrm{HT}_{2 \mathrm{C}}$ receptor. Lurasidone is rapidly absorbed (time to maximum plasma concentration: 1-3 hours), metabolized mainly by CYP3A4 and eliminated by hepatic metabolism. In two large, well-designed, 6-week trials in adult patients with bipolar 1 depression, lurasidone monotherapy and adjunctive therapy with mood stabilizers were significantly more effective than placebo at improving depressive symptoms assessed using the Montgomery-Åsberg Depression Rating Scale total score. In both trials, lurasidone also reduced the Clinical Global Impression-Bipolar Severity depression score to a greater extent than placebo. In these two trials, discontinuation rates due to adverse events in the lurasidone group were small $(<7 \%)$ and were not different from those of the placebo group. The most common adverse events in the lurasidone group were headache, nausea, somnolence, and akathisia. The changes in lipid profiles, weight, and parameters of glycemic control were minimal, and these findings were in line with those observed in schizophrenia trials. Further active comparator trials and long-term tolerability and safety data in bipolar patients are required. Lurasidone may be an option for the management of depressive symptoms in patients with bipolar 1 disorder, and it may be considered as a treatment alternative for patients who are at high risk for metabolic abnormalities.

Keywords: lurasidone, bipolar disorder, acute depression, metabolic

\section{Introduction}

Bipolar disorder is a chronic and recurrent psychiatric disorder. ${ }^{1}$ Findings from recent studies generally indicate an overall lifetime prevalence of bipolar disorder of $1 \%-2.5 \% ;^{2-4}$ however, using broadened diagnostic criteria, recent studies reported much higher lifetime prevalence rates ranges from $4.5 \%-10.9 \% .{ }^{5}$ Moreover, these rates for bipolar spectrum disorders may be underestimated because they do not include patients with highly recurrent major depression - some of whom may fall within the bipolar spectrum. ${ }^{6}$

The natural course of bipolar disorder is variable; however, remission - the goal of treatment in bipolar disorder - is not easily achieved. The remission rate after acute treatment for mania is in the range of $40 \%-50 \%$, and for depression is $25 \%-60 \%$. $^{7}$ In a recent large cohort study, only $60 \%$ of patients achieved remission during a 2-year follow-up period. ${ }^{8}$ Chronic persistence of symptoms can be expected 
in about $20 \%$ of cases, and social incapacity in about $30 \%{ }^{6}$ Judd et $\mathrm{al}^{9}$ carried out a follow-up study over 13 years and reported that bipolar patients were symptomatic during about half of the follow-up period. Specifically, the frequent occurrence of subsyndromal symptoms has been noted in longitudinal studies. ${ }^{10-12}$ Subsyndromal symptoms have been associated with significant functional disability, ${ }^{13,14}$ and with an increased risk of relapse. ${ }^{15,16}$ Moreover, recurrence is not an exception rather than the rule. Almost all bipolar patients experience relapse, given adequate observation time. ${ }^{17}$ More than $90 \%$ of patients who have a single manic episode will have future episodes; ${ }^{18}$ about half of patients recur within 12 months after a mood episode, and the recurrence rate at 5 years is about $85 \% .^{18,19}$

Several treatments including antipsychotics, anticonvulsants, lithium, or electroconvulsive therapy have been reported to be efficacious and successful in the treatment of bipolar disorder. However, in reality, few drugs come close to being "true mood stabilizers" - agents that have acute efficacy in the treatment of manic, mixed, and depressive episodes - which are effective in preventing all types of episodes and residual symptoms. ${ }^{20}$ Classic mood stabilizers or anticonvulsants, including lithium and valproate, have been used as first-line therapies for acute and maintenance treatment of patients with bipolar 1 disorder. However, there is the need for more effective pharmacotherapy for acute depression and for the maintenance phase because bipolar depression is less responsive to classic mood stabilizers, ${ }^{21}$ and outcomes after relapse have been generally reported as poor. ${ }^{18,22,23}$ During the past decade, atypical antipsychotics have been the class of agents most studied across various phases of bipolar disorder, and updated treatment guidelines reflect an expanded role for atypical antipsychotics in bipolar disorder treatment.

Lurasidone was approved by the US Food and Drug Administration (FDA) in July 2013 for the treatment of bipolar depression as monotherapy, or in combination with lithium or valproate. However, at the time of writing this review (July 2013), we did not identify any clinical studies written on bipolar disorder and lurasidone that had been published in peer reviewed journals. There were only two Phase III studies noted, of which, the results were reported as poster presentations during international conferences. ${ }^{32,33}$ In this review, we will summarize the study results from these two Phase III bipolar depression studies, as well as present the results of preclinical and clinical trials of lurasidone from subjects with schizophrenia.

\section{Review of the pharmacology, mode of action, and pharmacokinetics of lurasidone}

Lurasidone is a chemical of the benzisothiazol class. It has full antagonistic properties at the dopamine (D) ${ }_{2}$ and serotonin $2 \mathrm{~A}\left(5-\mathrm{HT}_{2 \mathrm{~A}}\right)$ receptors like other second-generation antipsychotics. ${ }^{24}$ Lurasidone shows high selectivity at the $\mathrm{D}_{2}$ receptor when compared to the $\mathrm{D}_{1}, \mathrm{D}_{3}$, and $\mathrm{D}_{4}$ subtypes. ${ }^{25}$ Lurasidone also has partial agonistic properties of high affinity at the $5-\mathrm{HT}_{1 \mathrm{~A}}$ receptor. ${ }^{24}$ Lurasidone has much greater binding affinity at the $5-\mathrm{HT}_{7}$ receptor compared to other second-generation antipsychotics, and the blockade of this receptor subtype is also thought to contribute to lurasidone's antipsychotic actions. ${ }^{24,26}$ There have also been several studies that suggested the positive impacts of 5- $\mathrm{HT}_{7}$ antagonistic effects on memory ${ }^{27}$ and affective symptoms. ${ }^{28}$ Lurasidone has weak affinity for norepinephrine $\alpha_{2 \mathrm{C}}$ and the $5-\mathrm{HT}_{2 \mathrm{C}}$ receptor. ${ }^{29}$ The weak affinity for $\alpha_{2 \mathrm{C}}$ suggests a low probability of causing orthostatic hypotension, and the weak affinity for the $5-\mathrm{HT}_{2 \mathrm{C}}$ receptor suggests a low propensity of causing weight gain. ${ }^{24}$ Lurasidone poses negligible affinity at the muscarinic receptors and the histamine $\mathrm{H}_{1}$ receptors, which are associated with weight gain and sedation. ${ }^{24,30}$ The receptor profiles possessed by lurasidone mentioned above have been expected to explain lurasidone's efficacy, not only against positive and negative symptoms, but also for affective symptoms. ${ }^{29}$

After oral administration of lurasidone, it is rapidly absorbed. The time to maximum plasma concentration $\left(\mathrm{T}_{\max }\right)$, is about 1 hour to 3 hours. The bioavailability is from $9 \%$ to $19 \% ;^{29}$ however, pharmacokinetic studies showed that lurasidone absorption is influenced by food consumption. ${ }^{25}$ If administered with food, the exposure of lurasidone showed a twofold increase; the maximum concentration $\left(\mathrm{C}_{\max }\right)$ also increased by threefold. The $\mathrm{T}_{\max }$ is shown to increase by 0.5-1.5 hours with food. ${ }^{25}$ However, fat content in food and caloric intake did not seem to have an influence on the overall effect observed when taking lurasidone with food. ${ }^{25,29}$ Considering the significant food effect on the bioavailability of lurasidone, lurasidone is recommended to be administered once daily with at least 350 calories of food. ${ }^{26}$

After absorption of lurasidone distributes extensively in tissues. ${ }^{24}$ It showed a dose-dependent increase in the occupancy of the $\mathrm{D}_{2}$ receptor until a dose of $60 \mathrm{mg}$ of lurasidone was reached (77.4\%-84.3\%); however, after $80 \mathrm{mg}$, it showed no further increase in the $\mathrm{D}_{2}$ receptor occupancy at the $\mathrm{T}_{\max }$ among healthy subjects. ${ }^{31} \mathrm{D}_{2}$ occupancy among healthy male subjects was $63.1 \%-67.5 \%, 77.4 \%-84.3 \%$, and 
$72.9 \%-89.9 \%$ after a single administration of $40 \mathrm{mg}, 60 \mathrm{mg}$, and $80 \mathrm{mg}$, respectively. ${ }^{25}$ Lurasidone showed $99.5 \%$ protein binding, and it also binds to $\alpha_{1}$ glycoprotein and albumin. ${ }^{31}$

Lurasidone is metabolized primarily by CYP3A4 into several metabolites, including the hydroxylated derivative ID-20220, the acidic derivative ID-20219, ID-14326, ID-11614 (BITP), and ID-14283. Both ID-20219 and ID-20220 have been found to have negligible affinity at the $5-\mathrm{HT}_{1 \mathrm{~A}}, 5-\mathrm{HT}_{2 \mathrm{~A}}$, and $5-\mathrm{HT}_{7}$ receptor subtypes. ${ }^{24} \mathrm{ID}-11614$ also has low affinity at the $5-\mathrm{HT}_{2}$ receptor and the $\mathrm{D}_{2}$ receptor, and it does not have antipsychotic action in preclinical tests. ${ }^{24}$ Conversely, both ID-14283 and ID-14326 have binding affinity at the $\mathrm{D}_{2}$ and $5-\mathrm{HT}_{2 \mathrm{~A}}$ receptors, which is similar to lurasidone. They also have high binding affinity at 5- $\mathrm{HA}_{1 \mathrm{~A}}$ and $5-\mathrm{HT}_{7}$, which is comparable to lurasidone. Both metabolites, especially ID-14283, seem to contribute to the antipsychotic action of lurasidone. ${ }^{24,26}$ The $\mathrm{T}_{\text {max }}$ of ID-14283 is 1.6 hours to 1.8 hours, and its half-life $\left(\mathrm{T}_{1 / 2}\right)$ is $7.48-10$ hours. ${ }^{26,31}$

Lurasidone is eliminated mainly by hepatic metabolism. ${ }^{26}$ Among schizophrenia patients, the $T_{1 / 2}$ ranges from 28.8-37.4 hours after administration of a single dose with $120 \mathrm{mg} /$ day to $160 \mathrm{mg} /$ day. Among healthy volunteers, however, the $T_{1 / 2}$ is 12.2 hours to 18.3 hours after singledose administration of $100 \mathrm{mg}$ or less. However, the $\mathrm{T}_{1 / 2}$ increases up to 36 hours on the 9th day after continuous dose administration. ${ }^{26}$ A steady state was reached within 7 days. ${ }^{26}$

Lurasidone exposure between older adults with psychosis and younger patients was comparable after the administration of $20 \mathrm{mg}$ /day of lurasidone. Thus, like other atypical antipsychotics, dose adjustment in the elderly is not necessary. So far, the pharmacokinetics of lurasidone have not been investigated among adolescent and pediatric patients. ${ }^{24}$ Renal impairment is known to cause an increase in exposure to lurasidone. Compared to healthy controls, mild, moderate, and severe kidney disease caused a mean $\mathrm{C}_{\max }$ increase of $40 \%, 92 \%$, and $54 \%$, respectively. It also caused a mean increase in plasma exposure, which was calculated using area under the curve (AUC), of 53\%, 91\%, and 100\%, respectively. With an increased severity of kidney impairment the $\mathrm{T}_{1 / 2}$ was prolonged. Thus, taken together, the manufacturer recommended that the doses of lurasidone should not exceed $40 \mathrm{mg}$ among moderate to severe cases of renal impairment. In addition, $40 \mathrm{mg}$ should not be exceeded among patients with moderate to severe hepatic impairment. In comparison to healthy controls, it was found that mild, moderate, and severe hepatic impairment caused a mean increase in $\mathrm{C}_{\max }$ of 1.3 times, 1.2 times, and 1.3 times, respectively. Mild, moderate, and severe hepatic impairment also caused an increase in the mean AUC of 1.5 times, 1.7 times, and three times higher, respectively. The mean $T_{1 / 2}$ among patients with hepatic impairment of moderate severity was greater than among healthy controls (112 hours versus 93 hours); however, there have been no data regarding the $\mathrm{T}_{1 / 2}$ among severe hepatic impairment. ${ }^{24}$

Lurasidone should be used with caution when coadministered with CYP3A4 inhibitors or inducers. ${ }^{24} \mathrm{~A}$ moderate CYP3A4 inhibitor appeared to double the $\mathrm{C}_{\max }$ and AUC of lurasidone and its metabolite, ID-14283, in healthy adults; whereas, rifampin (600 mg/day) (the CYP3A4 inducer) was shown to reduce lurasidone exposure by $85 \%$ after a single-dose administration of $40 \mathrm{mg}$ of lurasidone among healthy adults. ${ }^{24}$

\section{Therapeutic efficacy}

The efficacy of lurasidone in the treatment of depressive episodes in adults with bipolar disorder has been investigated in two Phase III randomized, double-blind trials, ${ }^{32,33}$ and lurasidone was recommended as a second-line treatment for bipolar 1 depression in a recently published treatment guideline (Table 1). ${ }^{34}$ The results from the two Phase III studies are not yet published in peer reviewed journals; thus, this review is largely based on two abstracts that were not peer reviewed.

One of these trials (the Program to Evaluate Antidepressant Impact of Lurasidone [PREVAIL]-1 study ${ }^{32}$ ) evaluated the efficacy and safety of adjunctive lurasidone in patients with bipolar 1 depression. During a 6-week double-blind treatment, $20-120 \mathrm{mg} /$ day of lurasidone (number $[\mathrm{N}]=183$ ) or placebo $(\mathrm{N}=165)$ was added to lithium or valproate. This trial enrolled adults with a Diagnostic and Statistical Manual of Mental Disorders, 4th Edition, Text Revision diagnosis of bipolar 1 disorder and who remained symptomatic (with a Montgomery-Åsberg Depression Rating Scale [MADRS] score $\geq 20$ ) following at least 4 weeks of treatment with either lithium or valproate, two commonly used mood stabilizers. $^{32}$

As adjunctive therapy, lurasidone with lithium or valproate improved depressive symptoms in bipolar 1 disorder. MADRS scores reduced from baseline to 6 weeks to a significantly greater extent than placebo. At baseline, the MADRS scores were similar for lurasidone (30.6) and placebo (30.8). The MADRS score reduction in the lurasidone group was -17.1 and was significantly greater than that of the placebo group $(-13.5 ; P<0.01)$ at week 6 . Adjunctive lurasidone also reduced the Clinical Global Impression-Bipolar Severity (CGI-BP-S) depression score by -2.0 points versus -1.5 points for placebo $(P<0.01)$. At the end of the 6 -week 


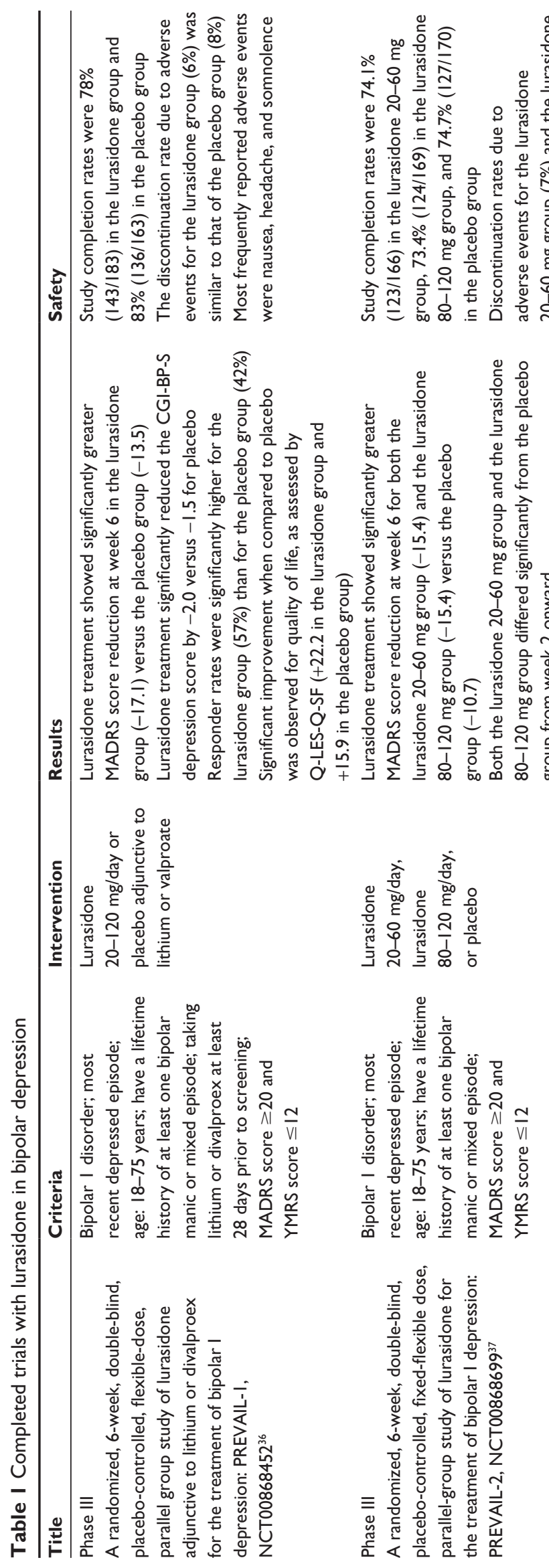


study period, when compared to placebo, lurasidone recipients achieved significantly higher MADRS response $(57 \%$ versus $42 \% ; P<0.01$ ).

The monotherapy trial (PREVAIL-2 study ${ }^{33}$ ) enrolled patients with a Diagnostic and Statistical Manual of Mental Disorders, 4th Edition, Text Revision diagnoses of bipolar 1 disorder and who were currently experiencing a depressed episode, with or without rapid cycling, and who had a MADRS score $\geq 20$ and who had a Young Mania Rating Scale score $\leq 12$. Eligible patients were randomized to 6 weeks of a once-daily, double-blind treatment with either lurasidone (20-60 mg; $\mathrm{N}=166$ ), lurasidone (80-120 mg; $\mathrm{N}=169$ ), or placebo $(\mathrm{N}=170) .{ }^{33}$ Monotherapy with lurasidone for both the 20-60 mg group and the 80-120 mg group improved depressive symptoms in bipolar 1 patients, reducing the MADRS total scores from baseline to 6 weeks to a significantly greater extent than placebo. At the end of the 6-week trial, mean changes from baseline in the MADRS total score were $-15.4(P<0.001)$ in the lurasidone $20-60 \mathrm{mg}$ group and $-15.4(P<0.001)$ in the lurasidone $80-120 \mathrm{mg}$ group; these results were significantly greater than that of the placebo group (-10.7). With respect to monotherapy, improvements in the MADRS score were significant from week 2 onwards in both of the lurasidone dose groups. Lurasidone treatment resulted in significantly greater CGI-BP-S depression scores for both the lurasidone $20-60 \mathrm{mg}$ group $(-1.8 ; P<0.001)$ and the lurasidone $80-120 \mathrm{mg}$ group $(-1.7 ; P<0.001)$ when compared with the placebo group $(-1.1)$. MADRS response rates observed in the lurasidone $20-60 \mathrm{mg}$ group $(53 \% ; P<0.001)$ and in the lurasidone $80-120 \mathrm{mg}$ group $(51 \% ; P<0.001)$ were significantly greater than that of the placebo group (30\%) at week $6 .{ }^{33}$

In an analysis of anxiety symptoms among the PREVAIL-1 and PREVAIL-2 study populations, ${ }^{35}$ lurasidone also improved anxiety symptoms in bipolar depression, whether used adjunctively to mood stabilizers or as monotherapy. In the PREVAIL-1 trial, adjunctive treatment with lurasidone significantly reduced anxiety symptoms when compared with placebo, as indicated by the greater Hamilton Anxiety Rating Scale (HAMA) total score. Reduction of the HAMA total score in the lurasidone group was -8.0 , and -6.0 in the placebo group $(P=0.003)$. One hundred and eight patients (31.8\%) in this study met the criteria for moderate to severe anxiety (HAMA $\geq 18$ ) at baseline. The CGI-BP-S score was significantly higher in this subgroup (4.7) compared with patients with lower anxiety burden $(4.4 ; P<0.001)$. The response rate ( $\mathrm{a} \geq 50 \%$ reduction in HAMA scores) in the moderate-to-severe anxiety subgroup was significantly higher among the lurasidone group (68.8\%) than among the placebo group ( $47.1 \% ; P=0.016)$. In the PREVAIL-2 trial, when compared with placebo, both of the lurasidone dose groups demonstrated significant reductions in anxiety levels at the end of week 6 ; HAMA score reductions were -6.8 in the lurasidone $20-60 \mathrm{mg}$ group ( $P=0.001$ versus placebo), -6.3 in the lurasidone $80-120 \mathrm{mg}$ group $(P=0.015$ versus placebo), and -4.6 in the placebo group. One hundred sixty five patients (34.0\%) met the criteria for moderate to severe anxiety (HAMA $\geq 18$ ) at baseline. Similar to the findings from the PREVAIL-1study, the reported general severity of illness reflected by the CGI-BP-S score of this subgroup (4.7) in the PREVAIL-2 was significantly higher compared to patients with lower anxiety at baseline $(4.5 ; P<0.001)$. More lurasidone patients with moderate to severe anxiety at baseline $(52.0 \%)$ met anxiety treatment-responder criteria than patients with placebo (37.3\%), but the difference did not reach statistical significance $(P=0.102) .{ }^{35}$

To date, there is no published clinical trial regarding the efficacy of lurasidone in the treatment of bipolar mania or maintenance. Phase III trials in bipolar maintenance treatment are under way.

\section{Safety and tolerability}

There were no clinical studies on lurasidone and bipolar disorder published in peer reviewed journals so far. Thus, we will discuss the safety of lurasidone based on the results of previous studies conducted on schizophrenia or schizoaffective disorder that were published in peer reviewed journals, and we will address preliminary findings regarding its safety in bipolar disorder, as reported in several abstracts.

Lurasidone's safety, so far, has been assessed in short-term clinical trials and in a few long-term trials of lurasidone among schizophrenia or schizoaffective disorder patients. ${ }^{36-40}$ The clinical trials among bipolar disorder patients are currently being completed; however, limited evidence exists regarding the safety of lurasidone among these populations. ${ }^{24}$ Preliminary findings based on several short-term studies among schizophrenia patients suggest that lurasidone is tolerable and safe with a low discontinuation rate. ${ }^{24}$ Pooled analyses reported that about $8 \%$ of the subjects treated with lurasidone and $4 \%$ of the subjects treated with placebo discontinued their treatment prematurely because of adverse events. ${ }^{41}$ The most common adverse events reported in schizophrenia trials included somnolence, nausea, akathisia, parkinsonism, and sedation..$^{24,42} \mathrm{~A}$ few long-term studies also suggested that long-term treatment of lurasidone is well tolerated and safe among schizophrenia populations. ${ }^{39,40}$ 
Regarding extrapyramidal symptoms (EPS), short-term studies reported that EPS are more common in the subjects treated with lurasidone than in subjects treated with placebo ( $14.7 \%$ in the lurasidone group versus $5.1 \%$ in the placebo group) ${ }^{43}$ Akathisia was reported more frequently in the lurasidone group (15\%) as compared to the placebo group (3.3\%). ${ }^{43}$ Dystonia was observed in $4.7 \%$ of the lurasidone group compared with $0.7 \% \%$ of the placebo group..$^{43}$ The changes from baseline to the end of study period, however, were comparable for EPS (including for akathisia) between the lurasidone group and the placebo group. ${ }^{41,43,44}$

Regarding adverse events related to weight gain, lurasidone is known to cause minimal effects on body weight among schizophrenia popoulations. ${ }^{24}$ The short-term clinical trials reported a mean increase of body weight of $0.75 \mathrm{~kg}$ in the subjects treated with lurasidone compared with $0.26 \mathrm{~kg}$ in the subjects treated with placebo. ${ }^{24,43}$ The percentages of the subjects who showed a weight gain of $7 \%$ or more was $5.6 \%$ in the lurasidone group compared with $4 \%$ in the placebo group ${ }^{43}$ the weight gain did not seem to be dose related. ${ }^{24}$ Potkin et $\mathrm{al}^{36}$ found that mean weight changes were comparable between the lurasidone group and the ziprasidone group $(-0.29 \mathrm{~kg}$ versus $-0.16 \mathrm{~kg})$. The evidence regarding the long-term effect of lurasidone on weight gain is limited, however, lurasidone showed a favorable effect on body weight compared with quetiapine extended release (XR) or risperidone in two long-term schizophrenia trials. ${ }^{39,40}$

Lurasidone does not appear to influence clinically significant changes in glucose levels, or across other metabolic parameters..$^{29,45}$ The pooled data analysis from short-term schizophrenia studies showed that the mean increases of fasting glucose levels were $1.4 \mathrm{mg} / \mathrm{dL}$ in subjects treated with lurasidone and $0.6 \mathrm{mg} / \mathrm{dL}$ in subjects treated with placebo; this difference was not statistically significant. ${ }^{43}$ The adverse events related to fasting glucose level did not appear to be dose related. ${ }^{43} \mathrm{~A}$ comparison trial with ziprasidone ${ }^{36}$ showed similar changes in fasting glucose levels between the lurasidone group and the ziprasidone group $(+4.7 \mathrm{mg} / \mathrm{dL}$ versus $+4.8 \mathrm{mg} / \mathrm{dL}$ ). In a long-term study comparing lurasidone with risperidone, ${ }^{40}$ the median change of fasting glucose levels in the lurasidone group was $-0.5 \mathrm{mg} / \mathrm{dL}$, while that of the risperidone group was $3.0 \mathrm{mg} / \mathrm{dL}$. Another long-term study comparing lurasidone with quetiapine $\mathrm{XR}^{39}$ showed that lurasidone does not have a negative influence on glucose level when administered for a long-term period.

Regarding the adverse events related to dyslipidemia, there were no increases in the level of total cholesterol, low-density lipoprotein (LDL) cholesterol, and triglycerides reported in short-term studies. ${ }^{41,43}$ Furthermore, Potkin et $\mathrm{al}^{36}$ found that lurasidone appeared to be associated with a decrease in triglycerides $(-2.6 \mathrm{mg} / \mathrm{dL})$ when compared to an increase $(+22.4 \mathrm{mg} / \mathrm{dL})$ in the ziprasidone-treated group. The pooled data from five short-term studies showed that mean changes in triglycerides and total cholesterol of the lurasidone group $(-5.0 \mathrm{mg} / \mathrm{dL}$ and $-8.0 \mathrm{mg} / \mathrm{dL})$ were comparable to those of haloperidol $(-3.0 \mathrm{mg} / \mathrm{dL}$ and $-8.0 \mathrm{mg} / \mathrm{dL})$ and placebo $(-7.0 \mathrm{mg} / \mathrm{dL}$ and $-10.0 \mathrm{mg} / \mathrm{dL}) .{ }^{41}$ In a long-term comparison study with risperidone, the median change of triglyceride and LDL cholesterol levels in the lurasidone group were $-3.5 \mathrm{mg} / \mathrm{dL}$ and $-2.0 \mathrm{mg} / \mathrm{dL}$, respectively. ${ }^{40}$ Another long-term study among schizophrenia patients that compared lurasidone with quetiapine XR also confirmed that long-term treatment of lurasidone does not have any adverse influence on measures of triglyceride levels, or on total and LDL cholesterol levels. ${ }^{39}$

Lurasidone does not appear to cause clinically significant changes in the QT interval on electrocardiogram findings. ${ }^{29,42}$ There have been no studies that reported increases in QTc intervals of more than $500 \mathrm{~ms}$, and that reported clinically significant electrocardiographic findings. ${ }^{37,43,44}$ Comparisons with olanzapine and placebo in Meltzer et al's study ${ }^{38}$ showed that mean changes in the QTc interval for $40 \mathrm{mg}$ and $80 \mathrm{mg}$ of lurasidone were $+5.1 \mathrm{~ms}$ and $+4.5 \mathrm{~ms}$, which were comparable to those of placebo $(+3.8 \mathrm{~ms})$ and olanzapine $(+4.4 \mathrm{~ms}) .{ }^{38} \mathrm{In}$ long-term studies, there were no reports of clinically significant electrocardiogram abnormalities or significant increases in the QT interval. ${ }^{39,40}$

Short-term studies showed that lurasidone was associated with significant increases in prolactin levels. ${ }^{24}$ The pooled data from five short-term studies reported that the mean changes of prolactin levels were $1.1 \mathrm{ng} / \mathrm{mL}$ in the lurasidone group and $-0.6 \mathrm{ng} / \mathrm{mL}$ in the placebo group. ${ }^{41}$ However, the potential of lurasidone to cause an increase in prolactin levels seems to be lower than that of haloperidol. ${ }^{44}$ The mean changes in prolactin levels were greater among the haloperidol treatment group $(+8.5 \mathrm{ng} / \mathrm{mL})$, followed by olanzapine $(+3.7 \mathrm{ng} / \mathrm{mL})$, lurasidone $(+1.1 \mathrm{ng} / \mathrm{mL})$, and placebo $(-0.5 \mathrm{ng} / \mathrm{mL}) .{ }^{44} \mathrm{In}$ comparison with ziprasidone, it was shown that those in the lurasidone group demonstrated a greater increase in prolactin level than those in the ziprasidone group $(3.0 \mathrm{ng} / \mathrm{mL}$ versus $2.0 \mathrm{ng} / \mathrm{mL}){ }^{36} \mathrm{~A}$ long-term study comparing lurasidone with risperidone showed that the median changes of prolactin levels in the lurasidone group were $0 \mathrm{ng} / \mathrm{mL}$ among male subjects and $0.95 \mathrm{ng} / \mathrm{mL}$ among female subjects; these levels were lower than those of the risperidone group $(7.50 \mathrm{ng} / \mathrm{mL}$ in males and $26.40 \mathrm{ng} / \mathrm{mL}$ in females).$^{40}$ Another long-term study showed that the median change of prolactin levels in the 
lurasidone group was $+0.6 \mathrm{ng} / \mathrm{mL}$, while that of the quetiapine XR group was $-0.7 \mathrm{ng} / \mathrm{mL} .^{39}$

So far, there have not been any published articles in peer reviewed journals, except for several abstracts, regarding the safety and tolerability of lurasidone among bipolar disorder patients. However, we think that it is worth discussing the preliminary findings of two studies among bipolar patients. Calabrese et $\mathrm{al}^{32}$ performed a 6 -week, placebo-controlled, double-blind study (PREVAIL-1) to examine the efficacy and safety of lurasidone adjunctive therapy among patients with bipolar 1 depression who showed inadequate response to either valproate or lithium therapy. In this study, the discontinuation rates due to drug-related adverse events among the 346 subjects randomized were $6 \%$ in the lurasidone group and $8 \%$ in the placebo group. The common adverse events included nausea (17.5\% in lurasidone group versus $11.0 \%$ in the placebo group), headache $(10.4 \%$ in the lurasidone group versus $12.3 \%$ in the placebo group), and somnolence (8.7\% in the lurasidone group versus $4.3 \%$ in the placebo group). ${ }^{32}$ Loebel et al ${ }^{33}$ examined the effectiveness and tolerability of lurasidone monotherapy among the subjects with nonpsychotic bipolar 1 depression in a 6-week, placebocontrolled, double-blind study (PREVAIL-2). Among a total of 505 subjects randomized, the discontinuation rates were $25.9 \%$ (43/166) in the lurasidone 20-60 mg group, $26.6 \%$ $(45 / 169)$ in the lurasidone $80-120 \mathrm{mg}$ group, and $25.3 \%$ $(43 / 170)$ in the placebo group. The discontinuation rates due to adverse events were $7 \%$ in the lurasidone $20-60 \mathrm{mg}$ group, $6 \%$ in the lurasidone $80-120 \mathrm{mg}$ group, and $6 \%$ in the placebo group. The most common adverse events in the lurasidone 20-60 mg group were headache (14.0\%), nausea (10.4\%), and akathisia (7.9\%). The common adverse events in the lurasidone $80-120 \mathrm{mg}$ group were nausea (17.4\%), akathisia $(10.8 \%)$, and headache $(9.0 \%)$. The changes in lipid profiles, weight, and parameters of glycemic control were minimal. The findings of these two bipolar disorder studies were in line with those observed in schizophrenia trials, suggesting that lurasidone could also be safely used among bipolar disorder populations both as a monotherapy agent and as an adjunctive therapy. ${ }^{46}$

\section{Patient focused perspective}

A secondary analysis on quality of life (QoL) and functioning in patients with bipolar 1 depression was performed for the PREVAIL-1 and PREVAIL-2 studies. ${ }^{47}$ Functioning was assessed in the secondary analyses using the Sheehan Disability Scale (SDS) total score and subscores. QoL was assessed using the Quality of Life, Enjoyment, and Satisfaction scale short form (Q-LES-Q-sf). In PREVAIL-1, lurasidone adjunctive therapy resulted in significantly greater improvement in function, as demonstrated by an SDS total score change of -9.5 for lurasidone versus -7.0 for placebo $(P=0.012)$. Functional improvement was also observed in subscales of SDS; the SDS-social life subscore $(P=0.003)$ and the SDSfamily life/home responsibilities subscore $(P=0.003)$ were improved significantly when compared with the placebo group, and there was a nonsignificant trend towards improvement on the SDS-work/school subscore $(P=0.068)$.

QoL assessed by the Q-LES-Q-sf total score was also significantly improved by lurasidone treatment $(+22.2)$ when compared to placebo $(+15.9 ; P=0.003)$ during the 6-week study period. Also, a significantly higher proportion of subjects shifted from below normal to normal ( $\geq 52.3$ ) Q-LESQ-sf scores ([lurasidone group] 64.3\% versus [placebo group] $44.1 \% ; P=0.001)$. In the PREVAIL-2 trial, both lurasidone dose groups showed significant improvements in function at week 6. A reduction in the total SDS score exhibited a reduction for both the lurasidone $20-60 \mathrm{mg}$ group (-9.5; $P=0.003)$ and the lurasidone $80-120 \mathrm{mg}$ group $(-9.8 ; P<$ $0.001)$; these results were significantly greater than that of the placebo group (-6.3). Changes in the Q-LES-Q-sf total score in the placebo group was +12.8 , and that was significantly different from both the lurasidone $20-60 \mathrm{mg}$ group $(+19.3$; $P=0.001)$ and the lurasidone $80-120 \mathrm{mg}$ group $(+19.8$; $P=0.001)$. The proportion of patients who shifted from below normal to normal QLES-Q-sf scores were 55.3\% in the lurasidone $20-60 \mathrm{mg}$ group $(P<0.001)$ and $54.2 \%$ in the lurasidone $80-120 \mathrm{mg}$ group $(P<0.001)$; these results were significantly different from the proportion of patients from the placebo group (32.9\%) who demonstrated this change. ${ }^{47}$

\section{Conclusion}

Lurasidone is an atypical antipsychotic agent that was most recently approved by the FDA for schizophrenia and bipolar depression treatment. Lurasidone belongs to the benzisothiazol class, and exerts full antagonism at the $\mathrm{D}_{2}$ and $5-\mathrm{HT}_{2 \mathrm{~A}}$ receptors, like other second-generation antipsychotics. It has a partially agonistic effect among $5-\mathrm{HT}_{1 \mathrm{~A}}$ subtypes, and poses stronger binding affinity at the $5-\mathrm{HT}_{7}$ receptor and weak binding affinity at the $\alpha_{2 \mathrm{C}}$ and $5-\mathrm{HT}_{2 \mathrm{C}}$ receptor. ${ }^{24,29}$ The receptor profiles of lurasidone suggest the beneficial effects of lurasidone over affective symptoms, as well as lurasidone's favorable side effects, including low potential of sedation and weight gain. The bioavailability of lurasidone is increased with food; thus, it is recommended that lurasidone be administered with food. Lurasidone is metabolized 
primarily by CYP3A4; thus, it should be used with caution when coadministered with CYP3A4 inducers or inhibitors. For patients with renal and hepatic impairments, dose adjustment of lurasidone is necessary.

Lurasidone is established as an effective agent in the acute treatment of bipolar 1 depression as either a monotherapy or an adjunctive therapy used with lithium or valproate. The overall effect of lurasidone in reducing depressive severity, as measured by the MADRS, is not dissimilar from any other atypical antipsychotics approved by the FDA for bipolar depression treatment. Lurasidone was also effective in the treatment of anxiety symptoms in bipolar depression, and it improved quality of life and functioning. Moreover, although mainly based on the findings from schizophrenia studies, lurasidone appears to cause minimal effects on body weight, and it does not cause significant changes across metabolic parameters. Olanzapine (combined with fluoxetine) and quetiapine, the only two agents approved by the FDA for the treatment of bipolar depression, have been frequently related to changes both in body composition and on metabolic parameters; therefore, these unique properties of lurasidone can be beneficial in the treatment of bipolar depression.

\section{Disclosure}

The authors report no conflicts of interest in this work.

\section{References}

1. Keck PE, McElroy SL, Arnold LM. Bipolar disorder. Med Clin North Am. 2001;85(3):645-661, ix.

2. Akiskal HS. The bipolar spectrum: research and clinical perspectives. Encephale. 1995;21 Spec No 6:3-11. French.

3. Angst J. Epidemiology of the bipolar spectrum. Encephale. 1995;21 Spec No 6:37-42. French.

4. Bebbington P, Ramana R. The epidemiology of bipolar affective disorder. Soc Psychiatry Psychiatr Epidemiol. 1995;30(6):279-292.

5. Lee S, Ng KL, Tsang A. A community survey of the twelve-month prevalence and correlates of bipolar spectrum disorder in Hong Kong. J Affect Disord. 2009;117(1-2):79-86.

6. Goodwin FK, Jamison KR. Manic-Depressive Illness: Bipolar Disorders and Recurrent Depression. 2nd ed. New York, NY: Oxford University Press; 2007.

7. Beyer JL. An evidence-based medicine strategy for achieving remission in bipolar disorder. J Clin Psychiatry. 2008;69 Suppl 3:31-37.

8. Bowden CL, Perlis RH, Thase ME, et al. Aims and results of the NIMH systematic treatment enhancement program for bipolar disorder (STEP-BD). CNS Neurosci Ther. 2012;18(3):243-249.

9. Judd LL, Akiskal HS, Schettler PJ, et al. The long-term natural history of the weekly symptomatic status of bipolar I disorder. Arch Gen Psychiatry. 2002;59(6):530-537.

10. Denicoff KD, Smith-Jackson EE, Disney ER, Suddath RL, Leverich GS, Post RM. Preliminary evidence of the reliability and validity of the prospective life-chart methodology (LCM-p). J Psychiatr Res. 1997;31(5):593-603.

11. Paykel ES, Abbott R, Morriss R, Hayhurst H, Scott J. Sub-syndromal and syndromal symptoms in the longitudinal course of bipolar disorder. Br J Psychiatry. 2006;189:118-123.
12. Judd LL, Akiskal HS, Schettler PJ, et al. A prospective investigation of the natural history of the long-term weekly symptomatic status of bipolar II disorder. Arch Gen Psychiatry. 2003;60(3):261-269.

13. Dion GL, Tohen M, Anthony WA, Waternaux CS. Symptoms and functioning of patients with bipolar disorder six months after hospitalization. Hosp Community Psychiatry. 1988;39(6):652-657.

14. Judd LL, Akiskal HS, Schettler PJ, et al. Psychosocial disability in the course of bipolar I and II disorders: a prospective, comparative, longitudinal study. Arch Gen Psychiatry. 2005;62(12):1322-1330.

15. Martinez-Aran A, Vieta E, Torrent C, et al. Functional outcome in bipolar disorder: the role of clinical and cognitive factors. Bipolar Disord. 2007;9(1-2):103-113.

16. MacQueen GM, Marriott M, Begin H, Robb J, Joffe RT, Young LT. Subsyndromal symptoms assessed in longitudinal, prospective follow-up of a cohort of patients with bipolar disorder. Bipolar Disord. 2003;5(5):349-355.

17. Angst J. The course of affective disorders. II. Typology of bipolar manicdepressive illness. Arch Psychiatr Nervenkr. 1978;226(1):65-73.

18. Gitlin MJ, Swendsen J, Heller TL, Hammen C. Relapse and impairment in bipolar disorder. Am J Psychiatry. 1995;152(11):1635-1640.

19. Keller MB, Lavori PW, Coryell W, Endicott J, Mueller TI. Bipolar I: a five-year prospective follow-up. J Nerv Ment Dis. 1993;181(4): 238-245.

20. Keck PE Jr, McElroy SL. Redefining mood stabilization. JAffect Disord. 2003;73(1-2):163-169.

21. Bauer M, Ritter P, Grunze H, Pfennig A. Treatment options for acute depression in bipolar disorder. Bipolar Disord. 2012;14 Suppl 2: $37-50$.

22. Goldberg JF, Harrow M, Grossman LS. Course and outcome in bipolar affective disorder: a longitudinal follow-up study. Am J Psychiatry. 1995;152(3):379-384.

23. Strakowski SM, Sax KW, McElroy SL, Keck PE, Hawkins JM, West SA. Course of psychiatric and substance abuse syndromes co-occurring with bipolar disorder after a first psychiatric hospitalization. J Clin Psychiatry. 1998;59(9):465-471.

24. Caccia S, Pasina L, Nobili A. Critical appraisal of lurasidone in the management of schizophrenia. Neuropsychiatr Dis Treat. 2012;8: $155-168$.

25. Citrome L. Lurasidone for schizophrenia: a review of the efficacy and safety profile for this newly approved second-generation antipsychotic. Int J Clin Pract. 2011;65(2):189-210.

26. Risbood V, Lee JR, Roche-Desilets J, Fuller MA. Lurasidone: an atypical antipsychotic for schizophrenia. Ann Pharmacother. 2012;46(7-8):1033-1046.

27. Meneses A. Effects of the 5-HT7 receptor antagonists SB-269970 and DR 4004 in autoshaping Pavlovian/instrumental learning task. Behav Brain Res. 2004;155(2):275-282.

28. Guscott M, Bristow LJ, Hadingham K, et al. Genetic knockout and pharmacological blockade studies of the 5-HT7 receptor suggest therapeutic potential in depression. Neuropharmacology. 2005;48(4):492-502.

29. McIntyre RS, Cha DS, Alsuwaidan M, McIntosh D, Powell AM, Jerrell JM. A review of published evidence reporting on the efficacy and pharmacology of lurasidone. Expert Opin Pharmacother. 2012;13(11): $1653-1659$.

30. Ishibashi T, Horisawa T, Tokuda K, et al. Pharmacological profile of lurasidone, a novel antipsychotic agent with potent 5-hydroxytryptamine 7 (5-HT7) and 5-HT1A receptor activity. J Pharmacol Exp Ther. 2010;334(1):171-181.

31. Meyer JM, Loebel AD, Schweizer E. Lurasidone: a new drug in development for schizophrenia. Expert Opin Investig Drugs. 2009;18(11): $1715-1726$.

32. Calabrese JR, Loebel A, Cucchiaro J, et al. Lurasidone adjunctive to lithium or valproate for the treatment of bipolar I depression: results of the 6-week, double-blind, placebo-controlled PREVAIL-1study. Neuropsychopharmacology. 2012;38:S132. Available from: http://www. nature.com/npp/journal/v38/n1s/index.html. Accessed July 20, 2013. 
33. Loebel A, Cucchiaro J, Silva R, et al. Lurasidone monotherapy for the treatment of bipolar depression: results of the 6-week, double-blind, placebo-controlled PREVAIL-2 study. Neuropsychopharmacology. 2012;38:S422-S423. Available from: http:/www.nature.com/npp/ journal/v38/n1s/index.html. Accessed July 21, 2013.

34. Yatham LN, Kennedy SH, Parikh SV, et al. Canadian Network for Mood and Anxiety Treatments (CANMAT) and International Society for Bipolar Disorders (ISBD) collaborative update of CANMAT guidelines for the management of patients with bipolar disorder: update 2013. Bipolar Disord. 2013;15(1):1-44.

35. Hirschfeld RMA, Cucchiaro J, Pikalov A, et al. Effect of lurasidone monotherapy or adjunctive therapy on anxiety symptoms in patients with bipolar I depression. Neuropsychopharmacology. 2012;38: S423-S424. Available from: http://www.nature.com/npp/journal/v38/n1s/index. html. Accessed July 21, 2013.

36. Potkin SG, Ogasa M, Cucchiaro J, Loebel A. Double-blind comparison of the safety and efficacy of lurasidone and ziprasidone in clinically stable outpatients with schizophrenia or schizoaffective disorder. Schizophr Res. 2011;132(2-3):101-107.

37. Nakamura M, Ogasa M, Guarino J, et al. Lurasidone in the treatment of acute schizophrenia: a double-blind, placebo-controlled trial. J Clin Psychiatry. 2009;70(6):829-836.

38. Meltzer HY, Cucchiaro J, Silva R, et al. Lurasidone in the treatment of schizophrenia: a randomized, double-blind, placebo- and olanzapinecontrolled study. Am J Psychiatry. 2011;168(9):957-967.

39. Loebel A, Cucchiaro J, Xu J, Sarma K, Pikalov A, Kane JM. Effectiveness of lurasidone vs quetiapine XR for relapse prevention in schizophrenia: a 12-month, double-blind, noninferiority study. Schizophr Res. 2013;147(1):95-102.
40. Citrome L, Cucchiaro J, Sarma K, et al. Long-term safety and tolerability of lurasidone in schizophrenia: a 12-month, double-blind, activecontrolled study. Int Clin Psychopharmacol. 2012;27(3):165-176.

41. Cucchiaro J, Pikalov A, Ogasa M. Safety of lurasidone: pooled analysis of five placebo-controlled trials in patients with schizophrenia. Int J Neuropsychopharmacol. 2010;13(Suppl 1):217.

42. Citrome L. Iloperidone, asenapine, and lurasidone: a brief overview of 3 new second-generation antipsychotics. Postgrad Med. 2011;123(2): 153-162.

43. Samalin L, Garnier M, Llorca PM. Clinical potential of lurasidone in the management of schizophrenia. Ther Clin Risk Manag. 2011;7: 239-250.

44. Ehret MJ, Sopko M, Lemieux T. Focus on lurasidone: a new atypical antipsychotic for the treatment of schizophrenia. Formulary. 2010;45(10):313-317.

45. Kantrowitz JT, Citrome L. Lurasidone for schizophrenia: what's different? Expert Rev Neurother. 2012;12(3):265-273.

46. Citrome L. Lurasidone in schizophrenia: new information about dosage and place in therapy. Adv Ther. 2012;29(10):815-825.

47. Ketter TA, Cucchiaro J, Silva R, et al. Lurasidone for bipolar I depression: effects on quality of life and functioning. Neuropsychopharmacology. 2012;38:S169-170. Available from: http://www.nature.com/npp/journal/v38/n1s/index.html. Accessed July 21, 2013.
Neuropsychiatric Disease and Treatment

\section{Publish your work in this journal}

Neuropsychiatric Disease and Treatment is an international, peerreviewed journal of clinical therapeutics and pharmacology focusing on concise rapid reporting of clinical or pre-clinical studies on a range of neuropsychiatric and neurological disorders. This journal is indexed on PubMed Central, the 'PsycINFO' database and CAS.

\section{Dovepress}

The manuscript management system is completely online and includes a very quick and fair peer-review system, which is all easy to use. Visit http://www.dovepress.com/testimonials.php to read real quotes from published authors. 